\title{
Journaling about progress and errors
}

\author{
Dawn Nordquist*
}

\begin{abstract}
Drawing on mindset, belonging, and equity scholarship, a journaling assignment was developed as a low-stakes, writing-to-learn, formative assessment instructional tool for engaging students with content, normalizing mistakes, and supporting students during remotely scheduled online instruction for introductory linguistic analysis courses. Anecdotal data from student evaluations and instructor impressions suggest that journals provide high impact learning opportunities.
\end{abstract}

Keywords. journaling; growth mindset; normalization; inclusivity

1. Introduction. Nationally, approximately four in ten students entering an institution of higher education will not graduate within six years. Moreover, this graduation rate is disproportionately reflected among students from low-income households, students of color, and first generation students, resulting in disproportionate attrition rates from higher education institutions in general and in STEM fields in particular (Student Experience Project 2021). In an effort to address this inequity, scholars in education, psychology, and sociology have identified interventions that educators can implement to offset unequal graduation and retention rates. The interventions relate to signaling growth mindset, developing a sense of social belonging, and creating inclusive classroom climates for all students. These interventions benefit structurally disadvantaged students by signaling that they belong in college, by normalizing the struggles that college students experience, and by encouraging students' continued engagement and participation in the college classroom. In turn, these interventions positively affect the student's university experience, leading to higher GPAs, greater retention rates, and the maintenance of a diverse student population across disciplines.

The following sections briefly review the literature on growth mindset, social belonging, and inclusive environments. The review is then followed by a discussion of a journaling assignment that was informed by the research to support student learning during remote instruction. Student perceptions of the assignment and instructor impressions of the assignment's utility for introductory linguistic analysis courses are discussed, followed by a final reflection on future use of the assignment.

1.1. GROWTH MINDSET. Much of the research on growth mindset has focused on the individual and how to encourage students to adopt a growth mindset about their abilities. Students who assume that their intelligence or ability is fixed are typically closed off to learning and are less likely to improve compared to students who enter the classroom with a belief that their intelligence can develop (Dweck \& Leggett 1988). While that research focus remains relevant, more recent studies on growth mindset investigate the effect that the instructor and institutional growth mindset have on student success. For instance, Muenks et al. (2020) found that students who perceived that their instructor viewed student ability as fixed did not perform as well as their peers who felt that the instructor viewed all students as capable of improving or developing their ability in the course. Furthermore, instructor mindset can have disproportionate effects on structurally marginalized students. Canning et al. (2019) found that in classes where faculty selfreport having a growth mindset, racial achievement gaps are reduced by half. In Section 2, I will

\footnotetext{
* The author would like to thank the University of New Mexico's Student Experience Project team for providing support to explore instructional interventions in the classroom. The author is also grateful to an anonymous reviewer’s feedback on an earlier draft. Author Affiliation: University of New Mexico (nordquis@unm.edu).
} 
discuss how the journaling assignment attempts to signal instructor growth mindset in introductory linguistics analysis courses.

1.2. Social BELONGING AND INCLUSIVE ENVIRONMENT. Students who belong to structurally disadvantaged populations often arrive at the university questioning whether or not they belong in a university setting. These personal doubts affect students' motivation to take advantage of resources that other students readily take advantage of when they encounter obstacles in their collegiate careers. For instance, students who have a sense of belonging will come to office hours, seek out tutoring services, and form study groups in response to academic struggles. Students who lack a sense of belonging are more likely to work alone, continue to struggle, and see the results of their hard work as self-affirming, indicating that they do not belong in college. Ultimately, this latter group of students is likely to leave their chosen field or drop out of college altogether. Studies on social-psychological interventions indicate that achievement gaps can be closed by signaling student inclusion and by engaging students with the material (Tibbetts et al. 2016). In particular, employing pedagogical interventions that actively engage students in the classroom improves student performance on exams, on average, by half a letter grade compared to students in lecture only courses where class failure rates are on average about 1.5 times greater (Freedman et al. 2014). Moreover, active learning, high impact practices benefit disadvantaged students more (Kuh 2008), closing achievement gaps by $33 \%$ on examinations and by $45 \%$ on passing rates (Theobald et al. 2020). The studies cited in this section are meta-analyses and therefore collapse intervention types. What seems clear, however, is that a move away from traditional lecture is beneficial for all students but especially for structurally disadvantaged students, and inclusion starts with adopting pedagogies that reach all students. In the next section, I will discuss how the journaling activity attempts to address social belonging and inclusivity for all students.

2. Assignment details. At the end of the Spring 2020 semester, the University of New Mexico student body indicated through a university poll that they preferred a return to face-to-face instruction due to technical and personal challenges they experienced with remote learning. However, when it became apparent that face-to-face instruction would not be possible in Fall 2020, I aimed to create assignments that would foster the kinds of support students might receive in the physical classroom. In addition, because the University of New Mexico has a diverse student body comprised of structurally disadvantaged groups, ${ }^{1}$ it was important to provide additional forms of support in the face of pandemic demands that might exacerbate questions of belonging and growth mindset. One such intervention was a formative assessment journaling assignment aimed at learning (Vonderwell \& Boboc 2013) and at increasing engagement in online contexts (Poll, Widen \& Weller 2014).

The assignment asked students to periodically reflect on: 1) which skills they had mastered at a particular point in the semester; and, 2) several mistakes they had made on low-stakes assignments and how those mistakes had been beneficial to their learning in the class. More specifically, students were asked to state what they had learned, measured against a skill list for the course (see Zuraw, Aly, Lin, \& Royer [2019] for the value in creating a transparent list of course skills). Students also needed to state in their own words what they felt it was that they had mastered. Students were graded on whether or not they were able to be explicit about where/how/when they mastered a particular skill and what they specifically learned from mistakes made in analysis. It was believed

\footnotetext{
${ }^{1}$ UNM is a Hispanic Serving Institution with $45 \%$ of the student body identifying as Hispanic in 2020 . Another $5 \%$ of students are Native American (University of New Mexico Office of Institutional Analytics 2020). Additionally, 30\% of students received financial need-based Pell grants in 2019 (University of New Mexico Office of Institutional Analytics 2019).
} 
that, by asking students to journal about their progress and errors, several features of the above research would be addressed:

- INSTRUCTOR GROWTH MINDSET was implicitly signaled by normalizing mistakes as an expected part of the learning process. Errors are therefore treated as something that all students struggle with and are therefore implicitly valued in the classroom culture as part of the learning process. In other words, the assignment indicates that the instructor anticipates that all students will make mistakes in the class and that all students can learn from those mistakes. By extension, it is anticipated that a student of a structurally disadvantaged group will view their mistakes as normal, not as a reflection on their group membership or ability. Furthermore, the instructor expects all students to make mistakes but also expects all students can learn from those mistakes thereby implicitly signaling instructor growth mindset.

- SOCIAL BELONGING AND INCLUSIVITY was implicitly signaled by providing alternate forms of assessment that allow students to demonstrate learning in non-traditional formats (beyond only quizzes and exams). Because the journal assignment is a high impact practice which engages students with those aspects of the course that they find relevant to their own learning, social belonging is potentially cultivated. While all students can benefit from the implementation of such varied pedagogical tools, it is anticipated that marginalized groups will especially benefit from this instructional choice. Moreover, the grading rubric focused on student reflection and did not include any measure of student adherence to standard writing mechanics or other Anglo normative writing expectations (Inoue 2019). This may signal inclusivity by recognizing the language varieties students bring to the university setting.

3. Student reactions. End-of-the semester student evaluations provide some insight into student perceptions of the assignment. Response rates on these evaluations are typically low (no greater than about $60 \%$ of student enrollment), so this section is provisional. Students were asked to rate the usefulness of the journal assignment using a 5 point scale: VERY USEFUL (5), MODERATELY USEFUL (4), OCCASIONALLY USEFUL (3), RARELY USEFUL (2), NOT USEFUL AT ALL (1). Across three different classes in Fall 2020, the average ratings were: 3.16, 2.63, and 2.10. As a result, the exercise was rated on average as somewhere between OCCASIONALLY USEFUL and RARELY USEFUL. Students were also encouraged to provide written responses about their experience with the journaling exercise. Many students wrote that the journal assignment was good for reflection or useful for tracking their progress. A smaller number of students indicated that the assignment allowed for communication with the instructor or provided an opportunity to review for quizzes. These positive comments, however, were intermingled with negative perceptions of the assignment as being too time consuming or not relevant. The mixed feelings students had about the assignment is captured in (1), a paraphrase of one student's comments:

(1) I started keeping a list of breakthrough moments and I felt that this was burdensome but I actually realized in the end that I was really tracking my learning and that my grades in the class improved as a result. ${ }^{2}$

It is worth noting that student perceptions of what helps them learn are often at odds with what actually helps them learn. For example, active learning is negatively evaluated by students even

\footnotetext{
${ }^{2}$ Students did not consent for their comments to be used in a publication. Therefore, a paraphrase of the basic sentiment, as I understood it, is provided instead. All references to student examples in this paper are paraphrased or generalized across student responses.
} 
though active learning leads to better verified learning outcomes (Deslauriers et al. 2019). Therefore, the mixed feelings about the utility of the journaling exercise is not necessarily reason to abandon its implementation at this point. Experimental data should be collected to determine whether journaling is effective at improving learning outcomes.

4. Instructor impressions. Despite student comments that the journaling assignment was tedious, the journals were a worthwhile assignment for two unexpected reasons. First, the journals revealed gaps in student understanding that might have otherwise gone undetected in other assignment types. When students indicated that they had mastered a particular skill and then defined or exemplified the skill in their own words, many students revealed that their understanding was not complete (see Anderson [2016: e287] for a similar finding). For example, when discussing duplifixes, students often defined the term as "an affix that contains copied material as well as repeated consonant(s)", mistaking constant fixed material for consonant. While the error is likely the result of a mishearing or typo, students with no prior experience in linguistics could also internalize the misconception, even in the face of data sets to the contrary. Having access to student thinking through their writing provides the instructor with an opportunity to, at a minimum, draw attention to being detail-oriented in a linguistics course (constant vs. consonant), or more likely, address an actual gap in understanding. For instance, the example in (2) contains a paraphrase of the opening to one student's journal entry on subordinate clauses.

(2) I enjoy relative clauses which add more to the sentence because of the details they contribute to a sentence.

This student created a novel relative clause and accurately located its boundaries, but the semantic content of the relative clause (and adverbial clause) in the student entry shows a a lack of understanding of the function of a relative clause. The journal entry therefore affords the instructor an opportunity to respond early to the gap in understanding.

Second, student journal entries were useful for revealing some of the reasons for student mistakes, providing insight into student processing of course content. In a phonology journal entry, for example, one student indicated that they felt that pairs of items in the everyday world commonly complement one another, and therefore, the student had difficulty remembering that minimal pairs in a phonological data set would result in contrastive distribution. Another student shared that the gloss 1PL was difficult for them because the numeral in the gloss evoked singularity rather than first person for them. Not only does journal writing help students work through the content by actively engaging with the concepts, but the journals also allow the instructor to anticipate similar cognitive obstacles for other students and address them head on with the entire class and in future courses.

While these teaching moments are welcome, it was also apparent that students were often uncomfortable with writing about their mistakes as observed by the common self-evaluation that a mistake was "silly" or "stupid". It remains the case that much of higher education is delivered through traditional lecture, despite overwhelming evidence that such traditional lecture is not effective pedagogy. As a result, students are not generally accustomed to active-learning exercises such as journaling about progress and errors. In turn, it should probably not be a surprise that students resort to using self-critical negative evaluators of their work. If students are uncomfortable with reflecting on their errors, it is worth considering whether journaling might have a negative effect on student cognition. A negative cognitive state may adversely affect the intended purpose of the assignment, especially because much of the pedagogical rationale for the exercise is implicit. It may be worth discussing in explicit terms why the journaling assignment was selected (see De- 
slauriers et al. 2019 for an example of explicit delivery of course rationale for active learning pedagogy.)

5. Conclusions. It is not currently possible to conclude whether the journaling assignment directly signals instructor growth mindset or an inclusive classroom to students. Student reactions to the assignment's utility on end-of-the-semester Fall 2020 evaluations do not directly address these larger social-cognitive dimensions of the learning environment nor do they provide data on any correlation with positive learning outcomes. However, some preliminary data collected from the Student Experience Project (SEP) survey in Spring 2021indicates that students had very positive perceptions of instructor growth mindset, and moreover, these perceptions were especially strong among structurally disadvantaged students and among financially insecure students. Similar responses were reported for the SEP social belonging survey items although not as robustly as for instructor growth mindset questions. While identifying any causal role of the journaling assignment for these perceptions remains to be investigated, it is encouraging that students had positive perceptions of instructor mindset and social belonging during another semester when the journaling assignment was implemented. ${ }^{3}$ Nonetheless, future research should directly test the role that journaling plays in normalizing mistakes and whether the assignment leads to leveling the playing field for structurally disadvantaged students or whether it creates cognitive dissonance for different subsets of students. The Spring 2021 SEP data are consistent with the former scenario, but it seems prudent to include explicit discussion of the intervention in order to alleviate the potential for cognitive dissonance when reflecting on errors.

Finally, a serendipitous feature of the exercise was the feedback it provided to the instructor that she may not have otherwise detected through other formative assessments. In particular, the disclosures in student writing that revealed gaps in understanding served as a useful resource for early intervention to avoid compounding any misunderstandings. The journals were also valuable in revealing student thought processes and gave insight into potential cognitive obstacles. Both catching student misconceptions early on and identifying reasons for student learning obstacles were instructionally valuable and indispensable for maintaining a connection with students during remote learning.

\section{References}

Anderson, Catherine. 2016. Learning to think like linguists: A think-aloud study of novice phonology students. Language 92(4). e274-e291. https://doi.org/10.1353/lan.2016.0081.

Canning, Elizabeth, Katherine Muenks, Dorainne Green \& Mary Murphy. 2019. STEM faculty who believe ability is fixed have larger racial achievement gaps and inspire less student motivation in their classes. Science Advances 5. eaau4734. https://doi.org/10.1126/sciadv.aau4734.

Deslauriers, Louis, Logan S. McCarty, Kelly Miller, Kristina Callaghan \& Greg Kestin. 2019. Measuring actual learning versus feeling of learning in response to being actively engaged in the classroom. Proceedings of the National Academy of Sciences (PNAS) 116(39). 1925119257. https://doi.org/10.1073/pnas.1821936116.

Dweck, Carol S. \& Ellen L. Leggett. 1988. A social-cognitive approach to motivation and personality. Psychological Review 95(2). 256-273. https://doi.org/10.1037/0033-295X.95.2.256.

\footnotetext{
${ }^{3}$ Journals were twice mentioned by students in the Spring 2021 SEP written survey comments, but the mentions appeared in response to instructor fairness and feedback questions. However, no negative comments about the journals appeared in the SEP data collected for Spring 2021. UNM course-tailored student evaluations for Spring 2021 were not available at time of manuscript deadlines. Readers may contact the author with questions.
} 
Freeman, Scott, Sarah L. Eddy, Miles McDonough, Michelle K. Smith, Nnadozie Okoroafor, Hannah Jordt \& Mary Pat Wenderoth. 2014. Active learning boosts performance in STEM courses. Proceedings of the National Academy of Sciences (PNAS) 111(23). 8410-8415. https://doi.org/10.1073/pnas.1319030111.

Inoue, Asao B. 2019. Classroom writing assessment as an antiracist practice: Confronting white supremacy in the judgements of language. Pedagogy 19(3). 373-404. https://doi.org/10.1215/15314200-7615366.

Kuh, George D. 2008. High-impact educational practices: What they are, who has access to them, and why they matter. Washington, DC: Association of American Colleges and Universities.

Muenks, Katherine, Elizabeth Canning, Jennifer LaCosse, Dorainne Green, Sabrina Zirkel, Julie Garcia \& Mary Murphy. 2020. Does my professor think my ability can change? Students' perceptions of their STEM professors' mindset beliefs predict their psychological vulnerability, engagement, and performance in class. Journal of Experimental Psychology: General 149(11). 2119-2144. https://doi.org/10.1037/xge0000763.

Poll, Kathleen, Jeanne Widen \& Sherri Weller. 2014. Six instructional best practices for online engagement and retention. Journal of Online Doctoral Education, 1(1). 56-72.

Student Experience Project. 2021. About the SEP Fact Sheet. [Web page]. Accessed 3/25/2021: https://studentexperienceproject.org/resources/about-the-sep-fact-sheet/.

Theobald, Elli J., Mariah J. Hill, Elisa Tran, Sweta Agrawal, ... \& Scott Freeman. 2020. Active learning narrows achievement gaps for underrepresented students in undergraduate science, technology, engineering, and math. Proceedings of the National Academy of Sciences (PNAS) 117(12). 6476-6483. https://doi.org/10.1073/pnas.1916903117.

Tibbetts, Yoi, Judith M. Harackiewicz, Stacy J. Priniski \& Elizabeth E. Canning. 2016. Broadening participation in the life sciences with social-psychological interventions. Cell Biology Education 15(3), Es4. https://doi.org/10.1187/cbe.16-01-0001.

University of New Mexico Office of Institutional Analytics. 2020. Fact book, enrollment. [Web page]. Accessed 3/25/2021: https://public.tableau.com/app/profile/unm.oia/viz/UNMOfficialEnrollmentReport/Story1.

University of New Mexico Office of Institutional Analytics. 2019. Financial Aid. [Web page]. Accessed 3/25/2021: https://public.tableau.com/app/profile/unm.oia/viz/FinancialAid_10/Dashboard1.

Vonderwell, Selma K. \& Marius Boboc. 2013. Promoting formative assessment in online teaching and learning. TechTrends 57(4). 22-27. https://doi.org/10.1007/s11528-013-0673-x.

Zuraw, Kie, Ann M. Aly, Isabelle Lin \& Adam J. Royer. 2019. Gotta catch 'em all: Skills grading in undergraduate linguistics. Language 95(4). e406-e427. https://doi.org/10.1353/lan.2019.0085. 